\title{
Cerebral Blood Flow and Marrow Diffusion Alterations in Children with Sickle Cell Anemia after Bone Marrow Transplantation and Transfusion
}

\author{
(D) M.T. Whitehead, (D)A. Smitthimedhin, (D). Webb, DE.S. Mahdi, (D)Z.P. Khademian, (D).L. Carpenter, and (D)A. Abraham
}

\begin{abstract}
BACKGROUND AND PURPOSE: Hematopoietic marrow hyperplasia and hyperperfusion are compensatory mechanisms in sickle cell anemia. We have observed marrow diffusion and arterial spin-labeling perfusion changes in sickle cell anemia following bone marrow transplantation. We aimed to compare arterial spin-labeling perfusion and marrow diffusion/ADC values in patients with sickle cell anemia before and after bone marrow transplantation or transfusion.
\end{abstract}

MATERIALS AND METHODS: We reviewed brain MRIs from patients with sickle cell anemia obtained during 6 consecutive years at a children's hospital. Quantitative marrow diffusion values were procured from the occipital and sphenoid bones. Pseudocontinuous arterial spin-labeling perfusion values (milliliters/100 $\mathrm{g}$ of tissue/min) of MCA, anterior cerebral artery, and posterior cerebral artery territories were determined. Territorial CBF, whole-brain average CBF, and marrow ADC values were compared for changes before and after either bone marrow transplantation or transfusion. Bone marrow transplantation and transfusion groups were compared. Two-tailed paired and unpaired Student $t$ tests were used; $P<.05$ was considered significant.

RESULTS: Fifty-three examinations from 17 patients with bone marrow transplantation and 29 examinations from 9 patients with transfusion were included. ADC values significantly increased in the sphenoid and occipital marrow following bone marrow transplantation in contrast to patients with transfusion $(P>$.83). Whole-brain mean CBF significantly decreased following bone marrow transplantation (77.39 \pm 13.78 to $60.39 \pm 13.62 \mathrm{ml} / 100 \mathrm{~g}$ tissue/min; $P<.001$ ), without significant change thereafter. CBF did not significantly change following the first $(81.11 \pm 12.23$ to $80.25 \pm 8.27 \mathrm{ml} / 100 \mathrm{~g}$ tissue $/ \mathrm{min} ; P=.47)$ or subsequent transfusions. There was no significant difference in mean CBF between groups before intervention $(P=.22)$.

CONCLUSIONS: Improved CBF and marrow diffusion eventuate following bone marrow transplantation in children with sickle cell anemia in contrast to transfusion therapy.

ABBREVIATIONS: $\mathrm{ACA}=$ anterior cerebral artery; $\mathrm{ASL}=$ arterial spin-labeling; $\mathrm{BMT}=$ bone marrow transplantation; $\mathrm{PCA}=$ posterior cerebral artery; $\mathrm{SCA}=$ sickle cell anemia; $T 1=$ relaxation time

S ickle cell anemia (SCA) is an inherited hematopoietic disorder, rare in the general US population but more common in African Americans $(0.3 \% ; 1 / 365){ }^{1}$ The mutated hemoglobin contained in the red blood cells of patients with SCA (HbSS) forms insoluble polymers under low oxygen conditions and deforms the cells, giving them their sickle shape. The "sickle cells" have decreased deformability, rendering them unable to easily

Received June 17, 2018; accepted after revision August 15

From the Departments of Radiology (M.T.W., A.S., E.S.M., Z.P.K.), Hematology (J.W A.A.), and Neurology (J.L.C.), Children's National Medical Center, Washington, DC; and George Washington University Hospital (M.T.W., J.W., Z.P.K., J.L.C., A.A.), Washington, DC

Please address correspondence to Matthew T. Whitehead, MD, Department of Radiology, Children's National Medical Center, 111 Michigan Ave NW, Washington, DC 20010; e-mail: MWhitehe@childrensnational.org

http://dx.doi.org/10.3174/ajnr.A5830 pass through small vessels, and can reduce or occlude blood flow to tissues. Enhanced red blood cell production and blood flow are compensatory mechanisms used by the body in an attempt to maintain homeostasis. Hematopoietic marrow hyperplasia causes marrow signal alterations on MR imaging, including T1 lengthening, T2 shortening, and reduced diffusion. ${ }^{2-4}$ Elevated cardiac output, increased arterial blood flow, and vasodilation contribute to cerebral hyperperfusion. ${ }^{5}$ However, end organs remain vulnerable to ischemic injury because these compensatory adjustments are often insufficient. Furthermore, small- and largevessel vasculopathy can potentiate this rather tenuous situation. ${ }^{6}$ In the brain, injury may take the form of borderzone ischemia, focal small-vessel lacunar infarcts (symptomatic or silent), or large vascular territory infarctions.

Arterial spin-labeling (ASL) perfusion is a noninvasive MR imaging technique that uses flowing blood as an intrinsic tracer to 
assess cerebral blood flow in milliliters $/ 100 \mathrm{~g}$ of tissue/min. ${ }^{7-9}$ Thus, it is an MR imaging technique well-suited to the SCA population because it readily depicts the present state of blood flow to the brain without the need for intravenous gadolinium. In compensated patients with SCA, the combination of hyperperfusion and anemia leads to a generalized increase in ASL brain signal. The signal is then reduced in patients with cerebrovascular disease, including delayed arterial transit (eg, vasculopathy) and hypoperfusion (eg, ischemia or encephalomalacia), or increased in states of hyperperfusion (eg, luxury perfusion or seizure-related). ${ }^{8,10,11}$ Notable limitations of the ASL technique include a relatively poor signal-to-noise ratio and variables often represented as estimations in calculating the ASL perfusion equation, such as tagging efficiency, postlabel delay, the cortex-blood partition coefficient, and the T1 of blood. ${ }^{8}$ The latter, however, can be measured directly or calculated with knowledge of the magnetic field strength, hemoglobin, and oxygen saturation. ${ }^{12}$

Primary therapeutic measures in symptomatic patients with SCA include hydroxyurea, red blood cell transfusions, and, in the appropriate population, bone marrow transplantation (BMT), which is curative if successful. Human leukocyte antigenmatched sibling donors offer the best hope for a cure with BMT, with a success rate as high as $98 \% .{ }^{13}$ However, failure can occur in up to $10 \%$ and is more common with nonsibling human leukocyte antigen-matched donors and nonmatched donors. ${ }^{14-20}$ Repeat transplantation would be necessary under these circumstances to achieve success. Imaging markers for transplantation failure would thus be useful adjuncts to guide early treatment decisions.

We have observed changes in brain blood flow and marrow diffusion values following bone marrow transplant in SCA, potentially representing imaging biomarkers of a favorable therapeutic response. The aim of this study was to compare and contrast alterations in ASL perfusion and bone marrow diffusion/ ADC values in patients with SCA before and after BMT or initiation of chronic, monthly transfusion therapy.

\section{MATERIALS AND METHODS}

This Health Insurance Portability and Accountability Act-compliant retrospective study was performed after institutional review board approval. The brain MR imaging data base from a single academic children's hospital was queried for all examinations performed in patients with sickle cell anemia during a consecutive 6-year period (January 1, 2012, to December 31, 2017) using the terms "sickle cell," "ASL," and "arterial spin-labeling" to build a cohort for retrospective analysis. Each patient's medical record was reviewed to confirm a diagnosis of sickle cell disease, record demographic information, and determine the clinical course of the disease, including time points for transfusions and/or bone marrow transplantation. Each patient's most recent hematocrit and oxygen saturation levels relative to the time of the brain MR imaging were documented to correct for the longitudinal relaxation (T1) value of arterial blood. MR imaging examinations with excessive motion artifacts and technical limitations and without ASL images were excluded. Excessive motion artifacts were determined at the discretion of the board-certified neuroradiologist who reviewed each of the scans (M.T.W.) on the basis of training and experience. Motion artifacts were considered exces- sive when they limited either the ASL and/or DWI datasets more than a minimal-to-mild degree. Additional exclusion criteria included acute chest syndrome, acute stroke, posterior reversible encephalopathy syndrome, active infection, recent seizure, and vasculopathy based on MRA or transcranial Doppler (when MRA was unavailable). Cerebral hemispheres containing any chronic lesions larger than a lacunar infarct were excluded from analysis; in these cases, the contralateral hemisphere was evaluated in isolation. ASL perfusion images were evaluated qualitatively and quantitatively by a board-certified neuroradiologist with $>6$ years of clinical experience after board certification who was blinded to the type of therapy/intervention at the time of assessment.

Studies were performed on either a 1.5T (Discovery MR450 or Optima MR450W) or 3T (Discovery MR750) MR imaging scanner (GE Healthcare, Milwaukee, Wisconsin). The following sequences were performed through the brain in each examination: arterial spin-labeling perfusion, sagittal spoiled gradient-echo T1WI, axial T2WI, axial T2 FLAIR, axial DWI, and coronal fatsaturated T2WI. 3D TOF-MRA of the circle of Willis was also acquired concurrently with each brain MR imaging examination.

\section{DWI: Technique, Processing, and Assessment}

The bone marrow was evaluated qualitatively on T1, T2, and diffusion-weighted sequences. The T1WI and T2WI were assessed first to ensure lack of substantial marrow hypointensity reflecting transfusion-related iron deposition, which would interfere with the assessment of the DWI due to susceptibility. We excluded from further evaluation those with substantial marrow hypointensity defined as hypointense marrow signal with respect to muscle on all pulse sequences.

DWI acquisition parameters were as follows: TR, 10,000 ms; TE, 83-94 ms; flip angle, $90^{\circ}$; matrix, $128 \times 128 \mathrm{~mm}$; FOV, $24 \times$ $27 \mathrm{~cm}$; 1-2 excitations; section thickness, $5 \mathrm{~mm}$; spacing, 0. Qualitative marrow diffusion abnormalities were documented using a 3-point scale: 1, within normal limits; 2 , mild-to-moderate restricted diffusion; and 3, marked restricted diffusion. Quantitative apparent diffusion coefficient values (in square millimeters/ second) were measured using 4-mm circular ROIs placed manually in the marrow cavity of the right greater sphenoid wing and midline occipital bones; these representative sites were selected because the marrow cavity here is reliably thicker than in many other locations of the skull.

\section{ASL: Technique, Processing, and Assessment}

Each subject underwent pseudocontinuous ASL with background suppression and a segmented 3D fast spin-echo readout in accordance with current consensus guidelines ${ }^{7}$ using the following scan parameters: flip angle, $111^{\circ}-155^{\circ}$; inversion time/postlabel delay, 1025-1525 ms; labeling duration, 1500-2000 ms; TR, 4300-4600 ms; TE, $11 \mathrm{~ms}$; ETL (echo train length), 1; NEX, 2-3; matrix, $512 \times 8$; FOV , $24-55 \times 24-29 \mathrm{~cm}$; 32-35 slices; 3 - to $4-\mathrm{mm}$ slice thickness; 3- to 4-mm spacing; total sequence acquisition time, 4-5 minutes. Anatomic landmarks were used to select the labeling plane just below the inferior margin of the cerebellum. ASL postprocessing was performed on the MR imaging scanner. Grayscale ASL perfusion images and pseudocolor images were generated and displayed with age-dependent scaling based on the 
Table 1: Transplant group-hemoglobinopathy subtype, transplant data, and MR imaging data analyzed ${ }^{\mathrm{a}}$

\begin{tabular}{|c|c|c|c|c|c|c|c|c|c|}
\hline Pt & Diagnosis & Source & Donor & HLA Match & Scans (No.) & Age (yr) & DWI (No.) & $\begin{array}{c}\text { ASL (Right } \\
\text { Cerebrum) (No.) }\end{array}$ & $\begin{array}{c}\text { ASL (Left } \\
\text { Cerebrum) (No.) }\end{array}$ \\
\hline 1 & $\mathrm{HbSS}$ & $\mathrm{BM}$ & $\mathrm{R}$ & $8 / 8$ & 2 & 18,19 & 2 & 2 & 2 \\
\hline 2 & $\mathrm{HbSS}$ & BM & $\mathrm{R}$ & $8 / 8$ & 4 & $15,16,16,18$ & 4 & 4 & 4 \\
\hline 3 & HbS-BOTh & PBSC & $\mathrm{R}, \mathrm{H}$ & $4 / 8$ & 2 & 12,13 & 2 & 2 & 2 \\
\hline 4 & $\mathrm{HbSC}$ & BM & $\mathrm{R}$ & $8 / 8$ & 5 & $13,14,14,16,17$ & 5 & 5 & 5 \\
\hline 5 & HbSS & BM & $\mathrm{R}$ & $8 / 8$ & 4 & $7,10,11$ & 3 & 3 & 3 \\
\hline 6 & $\mathrm{HbSS}$ & BM & $\mathrm{R}$ & $8 / 8$ & 2 & 7,9 & 2 & 2 & 2 \\
\hline 7 & HbS-BOTh & BM & $\mathrm{R}$ & $8 / 8$ & 2 & 10,12 & 2 & 2 & 2 \\
\hline 8 & $\mathrm{HbSS}$ & BM & $\mathrm{R}$ & $8 / 8$ & 3 & $11,11,12$ & 3 & 2 & 2 \\
\hline 9 & $\mathrm{HbSS}$ & BM & $\mathrm{R}$ & $8 / 8$ & 4 & $5,7,8,9$ & 4 & 4 & 4 \\
\hline 10 & $\mathrm{HbSS}$ & UCB & $\mathrm{R}$ & $5 / 6$ & 4 & $8,8,9,10$ & 4 & 0 & 4 \\
\hline 11 & $\mathrm{HbSS}$ & $\mathrm{BM}$ & $\mathrm{R}$ & $8 / 8$ & 3 & $8,9,10$ & 3 & 3 & 3 \\
\hline 12 & $\mathrm{HbSS}$ & PBSC & $\mathrm{R}, \mathrm{H}$ & $3 / 6$ & 3 & $4,5,5$ & 3 & 0 & 3 \\
\hline 13 & $\mathrm{HbSS}$ & BM & $U$ & $8 / 8$ & 5 & $18,18,18,19,20$ & 5 & 3 & 3 \\
\hline 14 & $\mathrm{HbSS}$ & BM & $\mathrm{R}$ & $8 / 8$ & 2 & 1,2 & 2 & 2 & 2 \\
\hline 15 & $\mathrm{HbSS}$ & BM & $\mathrm{R}$ & $10 / 10$ & 3 & $3,3,3$ & 2 & 3 & 3 \\
\hline 16 & $\mathrm{HbSS}$ & BM & $\mathrm{R}$ & $8 / 8$ & 2 & 15,16 & 2 & 2 & 2 \\
\hline 17 & $\mathrm{HbSS}$ & UCB & U & $6 / 6$ & 3 & $3,3,4$ & 3 & 3 & 3 \\
\hline
\end{tabular}

Note:-Pt indicates patient; BM, bone marrow; PBSC, peripheral blood stem cell; UCB, umbilical cord blood; R, related; H, haploidentical; U, unrelated; HbSS, homozygous hemoglobin S; HbSC, sickle cell hemoglobin C; HbS-BOTh, hemoglobin S- $\beta$-thalassemia disease; HLA, human leukocyte antigen.

a SCA subtype, transplant information, total MRI scans, number of DWIs, and number of ASL sequences analyzed (right and left cerebral hemispheres) from 17 patients with transplants.

Table 2: Chronic transfusion group-hemoglobinopathy subtype and MR imaging data analyzed $^{\mathrm{a}}$

\begin{tabular}{lcccccc}
\hline Pt & Diagnosis & Scans (No.) & Age (yr) & DWI (No.) & $\begin{array}{c}\text { ASL (Right } \\
\text { Cerebrum) (No.) }\end{array}$ & $\begin{array}{c}\text { ASL (Left } \\
\text { Cerebrum) (No.) }\end{array}$ \\
\hline 1 & HbSS & 3 & $7,9,11$ & 0 & 3 & 0 \\
2 & HbSS & 6 & $0,1,2,5,6$ & 3 & 1 & 5 \\
3 & HbSS & 2 & 7,8 & 0 & 2 & 2 \\
4 & HbSS & 2 & 8,11 & 2 & 0 & 2 \\
5 & HbSS & 6 & $2,3,4,5,6,7$ & 0 & 6 & 6 \\
6 & HbSS & 2 & 4,6 & 1 & 2 & 2 \\
7 & HbSS & 2 & 6,8 & 1 & 2 & 2 \\
8 & HbSS & 3 & $3,4,5$ & 1 & 3 & 3 \\
9 & HbSS & 3 & $9,10,11$ & 0 & 3 & 3 \\
\hline
\end{tabular}

Note:-Pt indicates patient; HbSS, homozygous hemoglobin S.

a SCA subtype, total MRI scans, number of DWIs, and number of ASL sequences analyzed (right and left cerebral hemispheres) from 9 patients with transfusion.

magnitude of normal cerebral blood flow from the neonatal-toearly childhood period (younger than 1 year: $0-60 \mathrm{~mL} / 100 \mathrm{~g}$ of tissue/min; older than 1 year: $0-100 \mathrm{~mL} / 100 \mathrm{~g}$ of tissue/min). ${ }^{21}$

Arterial territory-specific quantitative ASL data in milliliters/100 $\mathrm{g}$ of tissue/min were procured using an AW workstation with FuncTool software (GE Healthcare). The T1 value of arterial blood was calculated in each patient using patient-specific hematocrit levels, oxygen saturation at or around the time of imaging (median, 2 days; range, $0-71$ days), and the magnetic field strength according to previously published guidelines. ${ }^{12}$ Then, 6 distinct manual ROIs were drawn around the cerebral cortex and subcortical white matter at the level of the basal ganglia to approximate each of the following vascular territories: anterior cerebral artery (right and left), middle cerebral artery (right and left), and posterior cerebral artery (right and left), using a previously established technique. ${ }^{22}$ Cerebral blood flow was calculated from the following equation:

$$
C B F=\frac{\lambda\left(1-e^{\frac{-t_{\mathrm{sat}}}{T_{1 \mathrm{~g}}}}\right)}{2 \alpha T_{1 \mathrm{~b}}\left(1-e^{\frac{-\tau}{T_{\mathrm{lb}}}}\right)} \frac{P W}{P D} e^{\frac{-P L D}{T_{1 \mathrm{~b}}}}
$$

where $\lambda$ indicates the cortex-blood partition coefficient $(0.9$, assumed); $t_{\text {sat }}$, time of saturation before imaging (2000 ms); $T_{1 \mathrm{~g}}, \mathrm{~T} 1$ of gray matter (1200 ms, assumed); $\alpha$, labeling efficiency $\left(0.8\right.$, assumed); $T_{1 b}$, $\mathrm{T} 1$ of the blood (calculated for each patient using the hematocrit, oxygen saturation, and magnetic field strength based on Hales et $\mathrm{al}^{12}$ ); $\tau$, labeling duration (1500 ms); PW, perfusion weighted signal intensity; $\mathrm{PD}$, proton density signal intensity; and PLD, postlabeling delay time. Mean whole-brain perfusion was estimated in each examination by averaging CBF values from all 6 evaluated territories. Gray-scale and corresponding postprocessed pseudocolor data were also evaluated together qualitatively. Qualitative cerebral signal magnitude was recorded using a 3-point scale: 1 , hypoperfusion; 2 , within normal limits; and 3, hyperperfusion.

\section{Statistical Methods}

The normal Gaussian distribution of the data mean was determined and confirmed by a Shapiro-Wilk test. Subsequently, 2-tailed paired $t$ tests were used separately in each group of patients with SCA before and after BMT and transfusion, respectively. Two-tailed unpaired $t$ tests were then performed to evaluate differences in the mean cerebral blood flow and marrow diffusion values between the posttransplantation and posttransfusion arms. The Wilcoxon signed rank test was used to evaluate paired samples of qualitative ordinal data. Observed power was calculated on the basis of the postintervention whole-brain CBF mean and SD differences between groups. $P \leq .05$ was considered significant.

\section{RESULTS}

Fifty-three brain MR imaging examinations from 17 patients with BMT (mean, 3; range, 2-5; mean length of follow-up, $1.9 \pm 0.9$ years; range, $0.7-4.2$ years) (9 male, 8 female) and 29 brain MR 

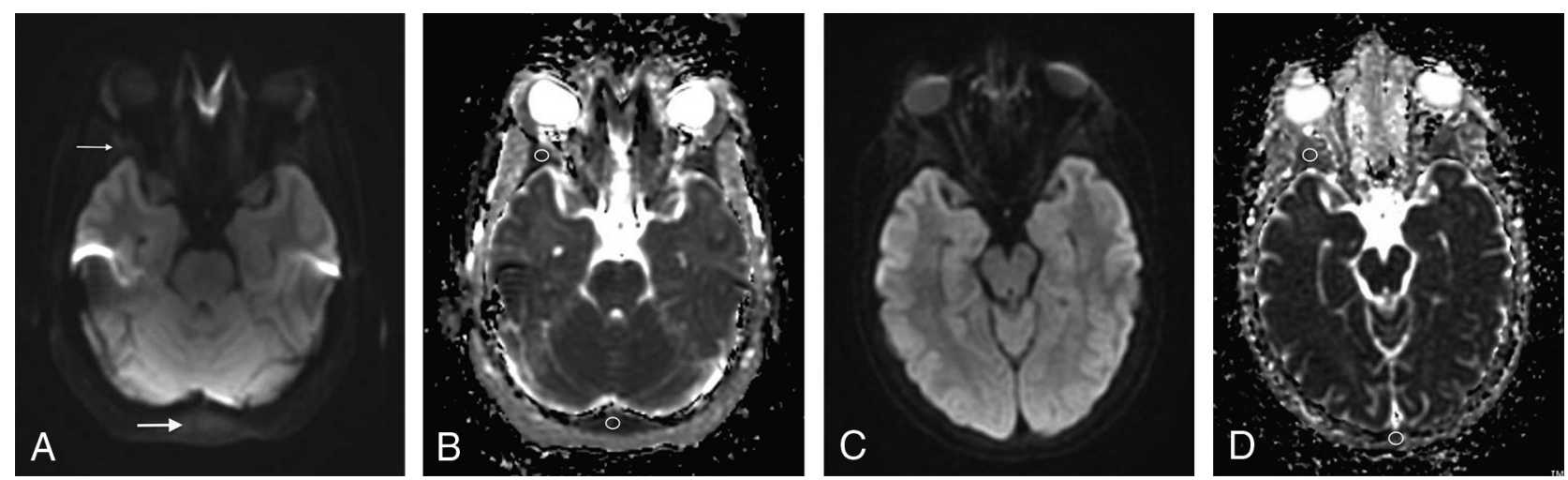

FIG 1. A 13-year-old girl with sickle cell disease. Pre-bone marrow transplantation axial DWI (A) (TR/TE $=10,000 / 83 \mathrm{~ms}$, slice thickness $=5 \mathrm{~mm})$ through the greater sphenoid wing (thin arrow) and occipital bone (thick arrow) and corresponding quantitative ADC map with ROIs (B) placed demonstrating reduced diffusion of the bone marrow. Follow-up MR imaging at 14 years of age from the same patient post-bone marrow transplantation with axial DWI (C) (TR/TE $=10,000 / 79.8 \mathrm{~ms}$, slice thickness $=5 \mathrm{~mm}$ ) at the same level as $A$ and corresponding quantitative ADC map $(D)$ demonstrating facilitated diffusion with respect to the pretransplantation scan.

Table 3: Pre- and posttransplantation ASL perfusion changes ${ }^{a}$

\begin{tabular}{|c|c|c|c|c|c|c|c|c|c|c|c|c|c|c|c|}
\hline \multirow[b]{2}{*}{ Pt } & \multicolumn{7}{|c|}{ Pretransplantation } & \multicolumn{7}{|c|}{ Posttransplantation } & \multirow[b]{2}{*}{$P$ Value } \\
\hline & MCA (R) & MCA (L) & $\mathrm{ACA}(\mathrm{R})$ & $\mathrm{ACA}(\mathrm{L})$ & PCA (R) & PCA (L) & Avg & MCA (R) & MCA (L) & $\mathrm{ACA}(\mathrm{R})$ & $\mathrm{ACA}(\mathrm{L})$ & PCA (R) & PCA (L) & Avg & \\
\hline 1 & 71 & 70 & 68 & 73 & 55 & 60 & 66 & 78 & 79 & 69 & 75 & 58 & 68 & 71 & $.02^{b}$ \\
\hline 2 & 92 & 82 & 88 & 85 & 96 & 89 & 89 & 74 & 78 & 70 & 73 & 61 & 65 & 70 & $.008^{c}$ \\
\hline 3 & 82 & 80 & 79 & 83 & 92 & 90 & 84 & 60 & 63 & 62 & 64 & 64 & 64 & 63 & $<.001^{\mathrm{c}}$ \\
\hline 4 & 66 & 63 & 64 & 60 & 50 & 51 & 59 & 34 & 35 & 37 & 38 & 28 & 30 & 34 & $<.001^{\mathrm{c}}$ \\
\hline 5 & 100 & 80 & 93 & 85 & 97 & 83 & 90 & 62 & 61 & 62 & 61 & 63 & 54 & 61 & $<.001^{\mathrm{c}}$ \\
\hline 6 & 90 & 89 & 96 & 93 & 87 & 91 & 91 & 81 & 77 & 74 & 70 & 71 & 73 & 74 & $<.001^{\mathrm{c}}$ \\
\hline 7 & 68 & 65 & 68 & 63 & 63 & 59 & 64 & 69 & 62 & 37 & 59 & 51 & 57 & 56 & .14 \\
\hline 8 & 76 & 72 & 73 & 67 & 73 & 73 & 72 & 59 & 54 & 56 & 52 & 48 & 46 & 53 & $<.001^{\mathrm{c}}$ \\
\hline 9 & 84 & 65 & 77 & 64 & 86 & 77 & 76 & 97 & 87 & 86 & 84 & 79 & 71 & 84 & .16 \\
\hline 10 & NA & 57 & NA & 56 & NA & 55 & 56 & NA & 45 & NA & 48 & NA & 40 & 44 & $.03^{c}$ \\
\hline 11 & 73 & 81 & 76 & 77 & 72 & 74 & 76 & 78 & 73 & 75 & 74 & 71 & 74 & 74 & .47 \\
\hline 12 & 89 & NA & 77 & NA & 100 & NA & 95 & 82 & NA & 72 & NA & 87 & NA & 80 & .07 \\
\hline 13 & 63 & 66 & 59 & 68 & 66 & 37 & 60 & 61 & 60 & 67 & 55 & 58 & 67 & 61 & .82 \\
\hline 14 & 85 & 81 & 79 & 76 & 77 & 74 & 79 & 77 & 79 & 65 & 70 & 62 & 63 & 69 & $.006^{\mathrm{c}}$ \\
\hline 15 & 68 & 71 & 67 & 72 & 63 & 64 & 68 & 64 & 65 & 63 & 62 & 53 & 50 & 60 & $.004^{c}$ \\
\hline 16 & 76 & 73 & 76 & 71 & 75 & 71 & 74 & 66 & 66 & 57 & 58 & 45 & 47 & 57 & $.005^{c}$ \\
\hline 17 & 100 & 99 & 101 & 94 & 91 & 94 & 97 & 40 & 40 & 37 & 37 & 35 & 37 & 38 & $<.001^{\mathrm{c}}$ \\
\hline $\mathrm{T}$ & 81 & 76 & 79 & 75 & 78 & 72 & 77 & 66 & 63 & 60 & 60 & 57 & 55 & 60 & $<.001^{\mathrm{c}}$ \\
\hline
\end{tabular}

Note:-Pt indicates patient; R, right; L, left; Avg, average/mean whole-brain CBF; NA, not applicable/excluded; T, mean of each arterial territory.

${ }^{a}$ Arterial territory-specific and mean whole-brain CBF values (in milliliters/100 g of tissue/min) from 17 patients with BMT prior to (left columns) and at the first scan after (right columns) transplantation. In the interest of space and simplicity, CBF values were rounded to the nearest whole number for this display.

bignificant increase in mean whole-brain CBF.

c Significant.

imaging examinations from 9 patient with transfusion (mean, 3; range, 2-6; mean length of follow-up, $3 \pm 1.4$ years; range, $1.1-$ 5.6 years) ( 3 male, 6 female) met the inclusion criteria (Tables 1 and 2). Two patients with transfusion were excluded; one lacked ASL, and the other had a severe vasculopathy with multiple infarctions and excessive motion artifacts. Three follow-up examinations after BMT were excluded from 2 different patients due to posterior reversible encephalopathy syndrome. One hemisphere was excluded from ASL analysis due to infarctions or vasculopathy in 4 cases from 2 patients in the transplant group and in 5 cases from 3 patients in the transfusion group; however, there was no significant difference between pre- and posttransfusion and preand posttransplantation CBF values between the subgroups that underwent unilateral and bilateral cerebral analysis. At the time of the initial MR imaging, the mean age of the BMT group was $9.8 \pm$ 5 years (range, $1-18$ years), while the mean age of the transfusion group was $6.3 \pm 4$ years (range, $0-9$ years) $(P=.13)$. Transfu- sions were initiated 20 days before the follow-up MR imaging on average (range, $4-60$ days). The mean time between BMT and the first follow-up MR imaging was $281 \pm 170$ days (range, 3-875 days). No patients who underwent BMT had graft failure.

\section{Marrow ADC Values}

ADC values significantly increased in the marrow of the greater sphenoid wing $\left(0.97 \pm 0.34\right.$ to $1.59 \pm 0.55 \times 10^{-3} \mathrm{~mm}^{2} / \mathrm{s} ; P=$ $.025)$ and occipital bone $\left(1.11 \pm 0.27\right.$ to $1.44 \pm 0.51 \times 10^{-3}$ $\mathrm{mm}^{2} / \mathrm{s} ; P=.043$ ) following bone marrow transplantation (Fig 1). Qualitatively, ADC sequences also demonstrated visually brighter marrow following BMT (the mean score decreased from 3 to 1 ), representing more facilitated diffusion $(P=.01428)$ (Fig 1). These changes were sustained across time on follow-up examinations, with no significant difference in the interval mean ADC values $(P>.05)$. There was no significant difference in sphenoid wing and occipital marrow mean ADC values be- 
tween patients pre- and posttransfusion $(P>.83)$; however, only 2 patients could be evaluated posttransfusion due to MR imaging evidence of marrow iron deposition. Post-BMT and posttransfusion marrow ADC values were significantly different from one another $(P=.0323)$. There was no significant difference between marrow ADC values obtained at $1.5 \mathrm{~T}$ and $3 \mathrm{~T}$ in either group $(P>.05)$.
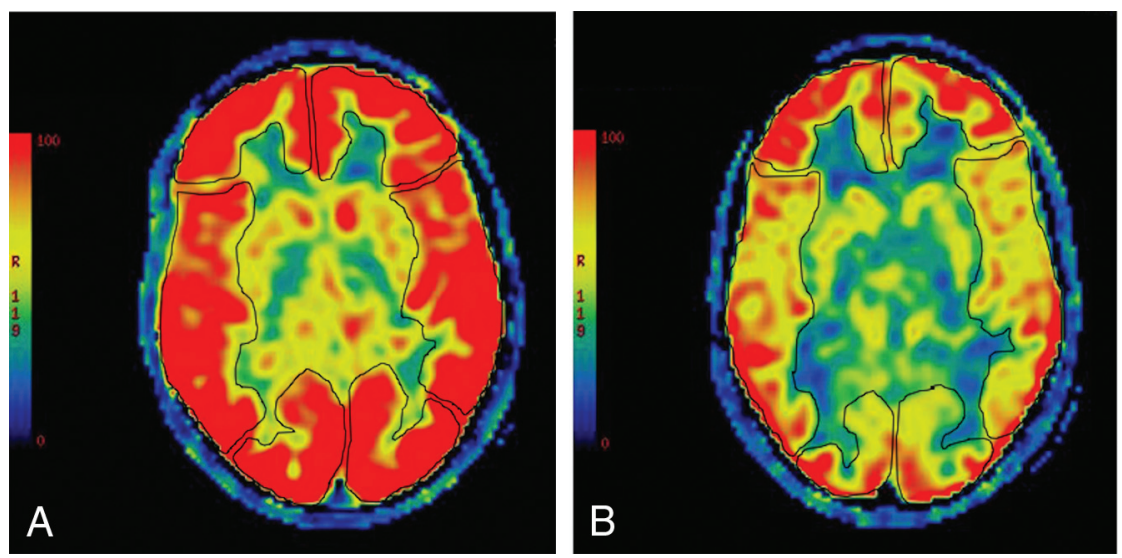

FIG 2. An 11-year-old boy with sickle cell disease. Pre-bone marrow transplantation, axial pseudocolor ASL $(A)$ depicts manual ROIs drawn to interrogate CBF from the bilateral ACA, MCA, and PCA territories. Diffusely increased signal is present throughout the cerebrum, consistent with elevated cerebral blood flow. Follow-up MR imaging at 12 years of age from the same patient, post-bone marrow transplantation, with axial pseudocolor ASL (B) depicting persistent-but-improved/decreased hyperperfusion.

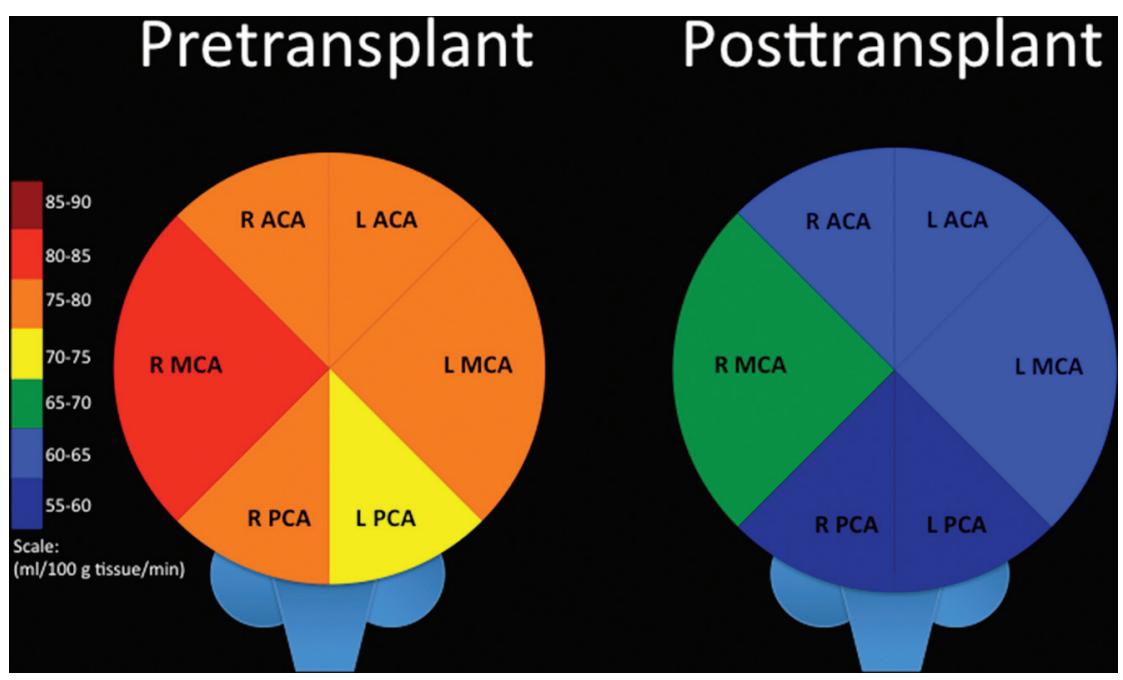

FIG 3. Comparison of arterial territory-specific quantitative mean $C B F$ in patients with $S C A$ before BMT (left) and at the first scan after BMT (right). R indicates right; L, left.

\section{Cerebral Blood Flow}

Preintervention mean whole-brain perfusion for both groups combined was $78.43 \pm 11.18 \mathrm{~mL} / 100 \mathrm{~g}$ of tissue/min. CBF values obtained at $1.5 \mathrm{~T}$ were not significantly different from those obtained at 3T in either group $(P>.05)$. There was no significant difference in mean quantitative cerebral blood flow between the BMT and transfusion groups before intervention $(P=.22)$. Mean whole-brain cerebral blood flow was significantly lower after BMT compared with transfusion $(P=.0004)$. The observed power was strong at $99.6 \%$.

Whole-brain mean quantitative cerebral blood flow significantly decreased following BMT, from $77.39 \pm 13.78$ to $60.39 \pm 13.62 \mathrm{~mL} / 100 \mathrm{~g}$ tissue $/ \mathrm{min}$ (first scan; $P=.00004$ ), and did not significantly change thereafter (Table 3 and Figs 2 and 3). The mean CBF significantly decreased in all bilateral vascular territories (anterior cerebral artery [ACA], MCA, posterior cerebral artery $[\mathrm{PCA}]$ ) on the first scan following BMT, and most of these significant differences were sustained across time. On an individual level, most patients (11/17) had a significant drop in whole-brain CBF on the first scan following BMT. Half of the patients who did not experience significantly decreased CBF on the first scan were reimaged at $\geq 1$ later time point; $\mathrm{CBF}$ ultimately decreased significantly in two-thirds of these patients. The first posttransplantation scan was performed at $0.8 \pm 6$ years on average

Table 4: Pre- and postinitiation of chronic transfusion therapy ASL perfusion changes ${ }^{a}$

\begin{tabular}{|c|c|c|c|c|c|c|c|c|c|c|c|c|c|c|c|}
\hline \multirow[b]{2}{*}{$\mathrm{Pt}$} & \multicolumn{7}{|c|}{ Pretransfusion } & \multicolumn{7}{|c|}{ Posttransfusion } & \multirow[b]{2}{*}{$P$ Value } \\
\hline & MCA (R) & MCA (L) & $\mathrm{ACA}(\mathrm{R})$ & $\mathrm{ACA}(\mathrm{L})$ & PCA (R) & PCA (L) & Avg & MCA (R) & MCA (L) & $\mathrm{ACA}(\mathrm{R})$ & ACA (L) & PCA (R) & PCA (L) & Avg & \\
\hline 1 & 96 & NA & 78 & NA & 93 & NA & 89 & 95 & NA & 94 & NA & 87 & NA & 92 & .69 \\
\hline 2 & 79 & 71 & 64 & 65 & 62 & 73 & 69 & NA & 87 & NA & 84 & NA & 80 & 84 & .06 \\
\hline 3 & 103 & 91 & 102 & 98 & 111 & 107 & 102 & 75 & 78 & 76 & 76 & 73 & 75 & 76 & $<.001^{\mathrm{b}}$ \\
\hline 4 & NA & 89 & NA & 80 & NA & 80 & 83 & NA & 75 & NA & 82 & NA & 76 & 78 & .37 \\
\hline 5 & 90 & 96 & 81 & 93 & 82 & 88 & 88 & 93 & 96 & 95 & 101 & 91 & 93 & 95 & $.02^{c}$ \\
\hline 6 & 84 & 102 & 88 & 100 & 78 & 83 & 90 & 79 & 96 & 81 & 86 & 78 & 76 & 83 & $.02^{\mathrm{b}}$ \\
\hline 7 & 98 & 93 & 88 & 90 & 92 & 88 & 92 & 81 & 84 & 74 & 85 & 74 & 83 & 81 & $.005^{b}$ \\
\hline 8 & 70 & 68 & 70 & 65 & 65 & 64 & 67 & 74 & 79 & 64 & 71 & 60 & 60 & 68 & .74 \\
\hline 9 & 70 & 70 & 64 & 66 & 63 & 71 & 67 & 69 & 74 & 77 & 85 & 73 & 80 & 87 & $.02^{c}$ \\
\hline $\mathrm{T}$ & 86 & 78 & 79 & 82 & 81 & 82 & 81 & 81 & 84 & 80 & 80 & 77 & 78 & 80 & .47 \\
\hline
\end{tabular}

Note:-Pt indicates patient; R, right; L, left; Avg, average/mean whole-brain CBF; NA, not applicable/excluded; T, mean of each arterial territory.

${ }^{a}$ Arterial territory-specific and mean whole-brain CBF values (in milliliters/100 g of tissue/min) from 9 patients with transfusion prior to (left columns) and at the first scan after (right columns) transfusion initiation. In the interest in space and simplicity, CBF values were rounded to the nearest whole number for this display.

b Significant.

'Significant increase in mean whole-brain CBF. 

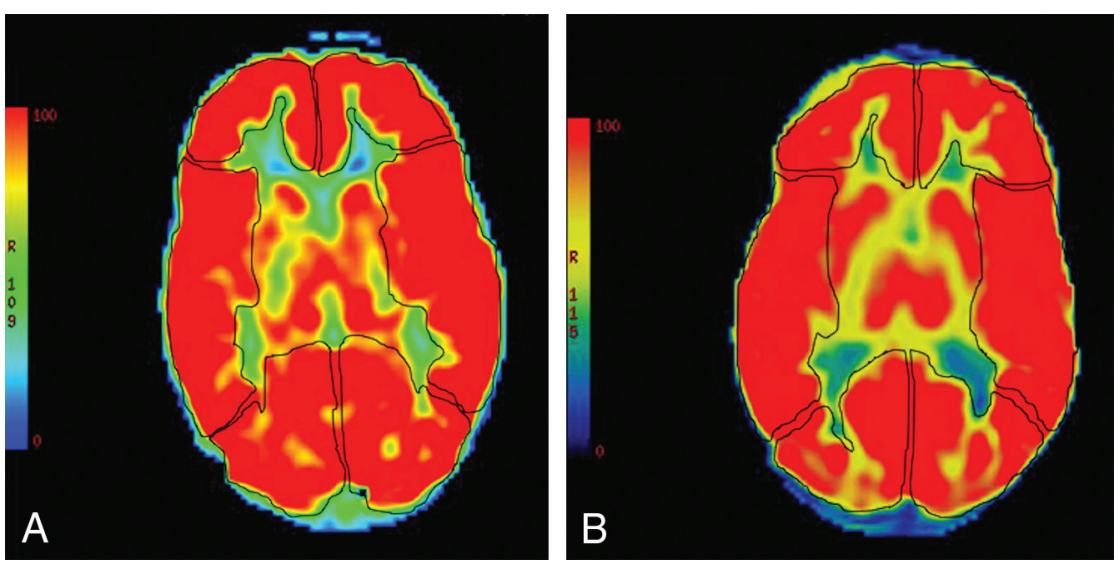

FIG 4. A 31-month-old girl with sickle cell disease. Pretransfusion axial pseudocolor ASL (A) depicts manual ROIs drawn to interrogate CBF from the bilateral ACA, MCA, and PCA territories. Diffusely increased signal is present throughout the cerebrum, consistent with elevated cerebral blood flow. Follow-up MR imaging at 36 months of age from the same patient at the same level posttransfusion with axial pseudocolor ASL $(B)$ depicting persistent hyperperfusion without significant change.

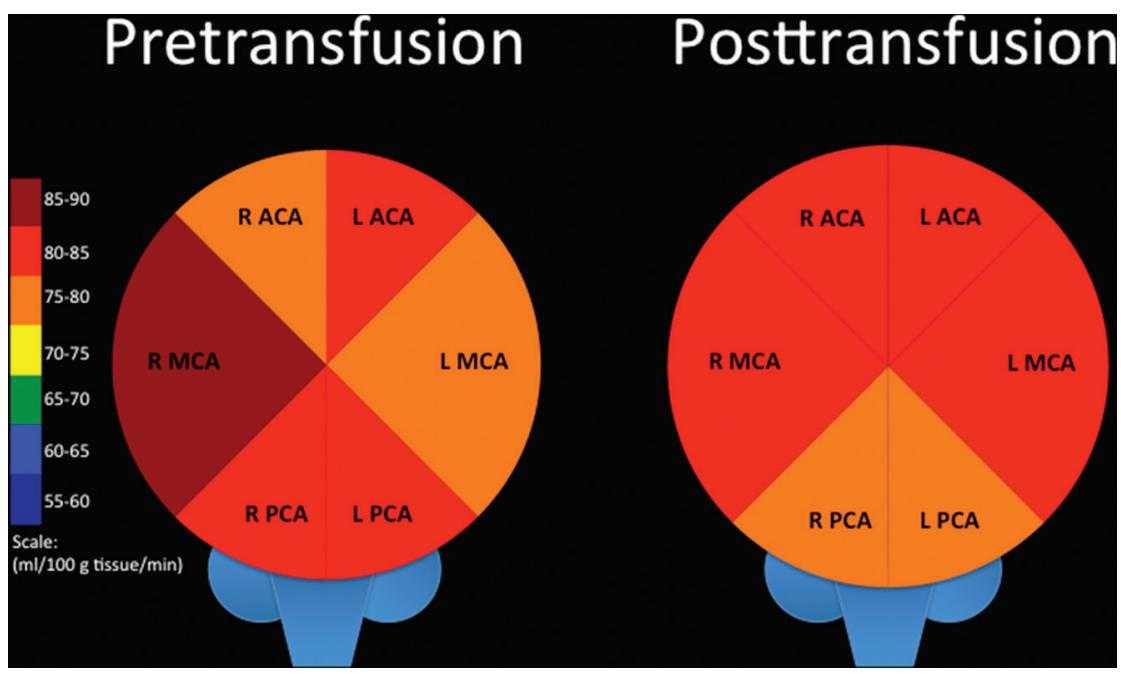

FIG 5. Comparison of arterial territory-specific quantitative mean CBF in patients with SCA before initial transfusion (left) and at the first scan after transfusion initiation (right). $\mathrm{R}$ indicates right; L, left.

after BMT. There was no significant difference in the time interval between transplant and the first posttransplantation brain MR imaging between patients who did and did not experience decreased CBF $(P=.5)$. One of the 6 patients without significant $\mathrm{CBF}$ alteration had an unrelated BMT without myeloablative preconditioning.

Whole-brain mean perfusion values did not significantly change following the first transfusion $(81.11 \pm 12.23$ to $80.25 \pm 8.27 \mathrm{~mL} / 100$ $\mathrm{g}$ tissue/min; $P=.47$ ) or across time after subsequent transfusions (Table 4 and Figs 4 and 5). Whole-brain CBF did not significantly decline in 6 of the 9 patients and actually significantly increased in 2 of these patients. A minority of patients (3/9) did experience significantly decreased whole-brain CBF after transfusion; unfortunately, none of these patients had further follow-up imaging to determine the duration of the change.

\section{DISCUSSION}

Marrow diffusion and cerebral perfusion significantly improved in patients with sickle cell anemia following bone marrow trans- plantation and did not change significantly after transfusion alone. Because marrow ADC values negatively correlate and $\mathrm{CBF}$ positively correlates with the severity of anemia, these may be useful surrogate imaging biomarkers for therapeutic success. ${ }^{2-4,12}$

Apparent diffusion coefficient values of bone marrow are inversely proportional to the degree of hematopoietic constituents. Red marrow hyperplasia causes $\mathrm{T} 1$ prolongation, $\mathrm{T} 2$ shortening, and reduced diffusion. ${ }^{2-4}$ Proliferative hematopoietic marrow changes in SCA are an attempt to compensate for the diminished oxygen-carrying capacity of the sickled erythrocytes and to replenish red blood cells prematurely removed from circulation. All patients in our cohort had evidence of reduced diffusion in the sphenoid and occipital bone marrow before intervention. Although SCAassociated quantitative ADC values in the skull have not been previously assessed in the literature to our knowledge, the significant increase in ADC and facilitated diffusion following BMT raises the possibility that marrow diffusion is reduced at baseline compared with age-expected values. These increased marrow ADC values were sustained across time on follow-up examinations after BMT, suggesting diminished or resolved hematopoietic marrow proliferation. No significant change in marrow ADC values was found in patients with SSA pre- to posttransfusion. However, interpretation was confounded because transfusion causes increased bone marrow $\mathrm{T} 1$ prolongation and T2 shortening due to iron deposition. ${ }^{2,3}$ Thus, we excluded examinations with qualitative marrow hypointensity from marrow DWI assessment. Unfortunately, in the transfusion group, this exclusion left only 2 patients for analysis.

The ASL signal magnitude is influenced by a number of factors in addition to blood flow, namely the spin-lattice relaxation time (T1) of arterial blood, blood flow velocity, labeling efficiency, and the brain-blood partition coefficient of water. The latter variable is difficult to accurately measure and is therefore typically estimated at $0.9 \mathrm{~mL} / \mathrm{g}$ for averaged brain gray and white matter. Labeling efficiency is inversely related to blood flow velocity and requires additional measurements for calculation, such as with phase-contrast imaging. However, the T1 of blood can and should be adjusted on a patient-to-patient basis, especially if there are known deviations from normal hematocrit. Anemia will prolong the T1 value of blood and cause spuriously increased ASL signal that, all other factors being equal, would be interpreted as hyper- 
perfusion. Arterial T1 values can be measured directly, but specific sequences are required at the time of MR imaging. ${ }^{23-25} \mathrm{Al}-$ ternatively, as used in our study, the $\mathrm{T} 1$ value can be calculated after determining the hematocrit, $\mathrm{O}_{2}$ saturation, and magnetic field strength. ${ }^{12}$

Cerebral perfusion decreases during childhood in normal states. ${ }^{26}$ It has been shown that anemia positively correlates with cerebral blood flow and negatively correlates with cerebrovascular reserve and that these relationships are strongly associated with anemia severity in children with SCA. ${ }^{5}$ In untreated patients with asymptomatic sickle cell anemia, cerebral blood flow is diffusely elevated relative to aged-matched healthy subjects without regard for age, manifested on ASL as diffusely increased brain signal. ${ }^{6}$ Before intervention, we estimated the mean whole-brain CBF in our SCA cohort (transfusion and BMT groups combined) to be elevated at $78 \pm 11 \mathrm{~mL} / 100 \mathrm{~g}$ of tissue/min $(64 \pm 14 \mathrm{~mL} / 100 \mathrm{~g}$ of tissue/min is considered normal). ${ }^{27}$ Previous literature reported quantitative whole-brain CBF values in patients with SCA to be in a similar range $(83-87 \pm 24 \mathrm{~mL} / 100 \mathrm{~g}$ of tissue/min), though different ASL techniques were used and anemia-related blood T1 value adjustments were not made in that study, possibly accounting for slightly higher reported values. ${ }^{6,28}$

Therapeutic measures in SCA include blood transfusions and allogenic bone marrow transplantation. The improved $\mathrm{O}_{2}$ delivery conferred by transfused normal red blood cells enhances cerebrovascular reserve, decreases the oxygen extraction fraction, and decreases CBF. ${ }^{5,23}$ Guilliams et $\mathrm{al}^{23}$ reported a significant mean CBF drop following transfusion, from 88 to $82 \mathrm{~mL} / 100 \mathrm{~g}$ of tissue/ min. A minority of patients in our cohort also experienced decreased CBF posttransfusion; however, the mean whole-brain CBF encompassing the entire group did not change significantly (from 81 to $80 \mathrm{~mL} / 100 \mathrm{~g}$ of tissue/min). It is unclear whether this finding could relate to a smaller sample size and/or differences in techniques among studies. In contrast, whole-brain CBF significantly decreased after BMT (from 76 to $63 \mathrm{~mL} / 100 \mathrm{~g}$ of tissue/ min) and was sustained across time on follow-up MR imaging. This change occurred as early as 3 days after transplantation and, therefore, could be a neuroimaging marker heralding favorable engraftment. Engraftment can be observed clinically from 1 to 4 weeks posttransplantation with the definition based on a sustained rebound in the absolute neutrophil count of $\geq 500 / \mu \mathrm{L}$ and platelet count of $\geq 20,000 / \mu \mathrm{L}^{29}$

Several study limitations should be noted. The sample size is relatively small due to the rarity of SCA-related BMT, the high prevalence of brain and vascular pathology factoring into exclusions, and the novelty of ASL. The posttransfusion bone marrow diffusion data were particularly sparse because iron deposition precluded accurate interpretation in most cases. In the few cases that required single cerebral hemisphere exclusion from analysis, contralateral cerebral ASL perfusion data could have been unreliable to some extent; however, there was no significant difference between pre- and posttransfusion and pre- and posttransplantation CBF values between the subgroups that underwent unilateral and bilateral cerebral analysis to suggest that unilateral cerebral hemisphere exclusion from analysis had any bearing on the results. Future studies with a larger number of subjects will be useful to confirm our findings. Increased blood velocity due to chronic anemia is a known cause of decreased labeling efficiency using ASL, which may have resulted in underestimation of absolute CBF. ${ }^{30,31}$ Because this was a retrospective study, we did not have corresponding phase data available to approximate labeling efficiency in each case. However, relative changes across time and between groups would be unaffected. In addition, we used a single rather than a multicompartmental model for quantitative ASL calculation, and we did not account for venous outflow effects in SSA. ${ }^{24,30}$

\section{CONCLUSIONS}

Improved cerebral blood flow and marrow diffusion ensue following bone marrow transplantation in children with sickle cell anemia. We found no significant alteration in CBF or marrow diffusion in patients with SCA who underwent transfusion therapy, though the sample size is a limitation. ASL perfusion and quantitative marrow diffusion values are useful posttherapeutic imaging biomarkers.

Disclosures: Allistair Abraham—UNRELATED: Grant: American Society of Hematology*. *Money paid to the institution.

\section{REFERENCES}

1. Sickle Cell Disease (SCD). Centers for Disease Control and Prevention. Updated August 31, 2016. https://www.cdc.gov/ncbddd/ sicklecell/data.html. Accessed September 14, 2018.

2. Elias EJ, Liao JH, Jara H, et al. Quantitative MRI analysis of craniofacial bone marrow in patients with sickle cell disease. AJNR Am J Neuroradiol 2013;34:622-27 CrossRef Medline

3. Saito N, Nadgir RN, Flower EN, et al. Clinical and radiologic manifestations of sickle cell disease in the head and neck. Radiographics 2010;30:1021-34 CrossRef Medline

4. Park S, Kwack KS, Chung NS, et al. Intravoxel incoherent motion diffusion-weighted magnetic resonance imaging of focal vertebral bone marrow lesions: initial experience of the differentiation of nodular hyperplastic hematopoietic bone marrow from malignant lesions. Skeletal Radiol 2017;46:675-83 CrossRef Medline

5. Kosinski PD, Croal PL, Leung J, et al. The severity of anaemia depletes cerebrovascular dilatory reserve in children with sickle cell disease: a quantitative magnetic resonance imaging study. $\mathrm{Br} \mathrm{J}$ Haematol 2017;176:280-87 CrossRef Medline

6. Arkuszewski M, Krejza J, Chen R, et al. Sickle cell anemia: reference values of cerebral blood flow determined by continuous arterial spin labeling MRI. Neuroradiol J 2013;26:191-200 CrossRef Medline

7. Alsop DC, Detre JA, Golay X, et al. Recommended implementation of arterial spin-labeled perfusion MRI for clinical applications: a consensus of the ISMRM perfusion study group and the European consortium for ASL in dementia. Magn Reson Med 2015;73:102-16 CrossRef Medline

8. Grade M, Hernandez Tamames JA, Pizzini FB, et al. A neuroradiologist's guide to arterial spin labeling MRI in clinical practice. Neuroradiology 2015;57:1181-202 CrossRef Medline

9. Deibler AR, Pollock JM, Kraft RA, et al. Arterial spin-labeling in routine clinical practice, Part 1: techniques and artifacts. AJNR Am J Neuroradiol 2008;29:1228-34 CrossRef Medline

10. Deibler AR, Pollock JM, Kraft RA, et al. Arterial spin-labeling in routine clinical practice, Part 2: hypoperfusion patterns. AJNR AmJ Neuroradiol 2008;29:1235-41 CrossRef Medline

11. Deibler AR, Pollock JM, Kraft RA, et al. Arterial spin-labeling in routine clinical practice, Part 3: hyperperfusion patterns. AJNR Am J Neuroradiol 2008;29:1428-35 CrossRef Medline

12. Hales PW, Kirkham FJ, Clark CA. A general model to calculate the spin-lattice (T1) relaxation time of blood, accounting for haemat- 
ocrit, oxygen saturation and magnetic field strength. J Cereb Blood Flow Metab 2016;36:370-74 CrossRef Medline

13. Gluckman E, Cappelli B, Bernaudin F, et al; Eurocord, the Pediatric Working Party of the European Society for Blood and Marrow Transplantation, and the Center for International Blood and Marrow Transplant Research. Sickle cell disease: an international survey of results of HLA-identical sibling hematopoietic stem cell transplantation. Blood 2017;129:1548-56 CrossRef Medline

14. Shenoy S, Eapen M, Panepinto JA, et al. A trial of unrelated donor marrow transplantation for children with severe sickle cell disease. Blood 2016;128:2561-67 CrossRef Medline

15. Dalle JH. Hematopoietic stem cell transplantation in SCD. C R Biol 2013;336:148-51 CrossRef Medline

16. Walters MC. Update of hematopoietic cell transplantation for sickle cell disease. Curr Opin Hematol 2015;22:227-33 CrossRef Medline

17. Fitzhugh CD, Abraham AA, Tisdale JF, et al. Hematopoietic stem cell transplantation for patients with sickle cell disease: progress and future directions. Hematol Oncol Clin North Am 2014;28:1171-85 CrossRef Medline

18. Angelucci E, Matthes-Martin S, Baronciani D, et al; EBMT Inborn Error and EBMT Paediatric Working Parties. Hematopoietic stem cell transplantation in thalassemia major and sickle cell disease: indications and management recommendations from an international expert panel. Haematologica 2014;99:811-20 CrossRef Medline

19. Dedeken L, Lê PQ, Azzi N, et al. Haematopoietic stem cell transplantation for severe sickle cell disease in childhood: a single centre experience of 50 patients. Br J Haematol 2014;165:402-08 CrossRef Medline

20. Gluckman E. Allogenic transplantation strategies including haploidentical transplantation in sickle cell disease. Hematol Am Soc Hematol Educ Program 2013;2013:370-76 CrossRef Medline

21. Wintermark M, Lepori D, Cotting J, et al. Brain perfusion in children: evolution with age assessed by quantitative perfusion computed tomography. Pediatrics 2004;113:1642-52 CrossRef Medline

22. Goetti R, O'Gorman R, Khan N, et al. Arterial spin labeling MRI for assessment of cerebral perfusion in children with moyamoya disease: comparison with dynamic susceptibility contrast MRI. Neuroradiology 2013;55:639-47 CrossRef Medline

23. Guilliams KP, Fields ME, Ragan DK, et al. Red cell exchange transfusions lower cerebral blood flow and oxygen extraction fraction in pediatric sickle cell anemia. Blood 2018;131:1012-21 CrossRef Medline

24. Wu WC, St Lawrence KS, Licht DJ, et al. Quantification issues in arterial spin labeling perfusion magnetic resonance imaging. Top Magn Reson Imaging 2010;21:65-73. CrossRef Medline

25. Václavů L, van der Land V, Heijtel DF, et al. In vivo T1 of blood measurements in children with sickle cell disease improve cerebral blood flow quantification from arterial spin-labeling MRI. AJNR Am J Neuroradiol 2016;37:1727-32 CrossRef Medline

26. Hales PW, Kawadler JM, Aylett SE, et al. Arterial spin labeling characterization of cerebral perfusion during normal maturation from late childhood into adulthood: normal 'reference range' values and their use in clinical studies. J Cereb Blood Flow Metab 2014;34: 776-84 CrossRef Medline

27. Wang J, Licht DJ. Pediatric perfusion MR imaging using arterial spin labeling. Neuroimaging Clin N Am 2006;16:149-67, ix Medline

28. Helton KJ, Paydar A, Glass J, et al. Arterial spin-labeled perfusion combined with segmentation techniques to evaluate cerebral blood flow in white and gray matter of children with sickle cell anemia. Pediatr Blood Cancer 2009;52:85-91 CrossRef Medline

29. Dallas MH, Triplett B, Shook DR, et al. Long-term outcome and evaluation of organ function in pediatric patients undergoing haploidentical and matched related hematopoietic cell transplantation for sickle cell disease. Biol Blood Marrow Transplant 2013;19:820-30 CrossRef Medline

30. Bush A, Chai Y, Choi SY, et al. Pseudo continuous arterial spin labeling quantification in anemic subjects with hyperemic cerebral blood flow. Magn Reson Imaging 2018;47:137-46 CrossRef Medline

31. Gevers S, Nederveen AJ, Fijnvandraat K, et al. Arterial spin labeling measurement of cerebral perfusion in children with sickle cell disease. J Magn Reson Imaging 2012;35:779-87 CrossRef Medline 